\title{
Application of concentration-area fractal method in static modeling of hydrocarbon reservoirs
}

\author{
Ferina Shafieyan ${ }^{1} \cdot$ Mohammad Abdideh $^{1}$
}

Received: 17 December 2017 / Accepted: 5 October 2018 / Published online: 13 October 2018

(c) The Author(s) 2018

\begin{abstract}
Separating and identifying various fractal communities are the most crucial steps in static reservoir modeling. There are different ways for the identification and separation which vary from simple statistical methods (on the basis of statistical parameters functions Function) to complicated fractal methods (on the basis of the spatial structure of data). Fractal geometry supplies new instruments to estimate hydrocarbon reservoir properties. In the last few years, fractal geometry is known as a new trick of human mind for identifying and analyzing behavioral and structural complexities of generally natural phenomena. One of the uses of fractal geometry is to estimate the threshold limit and the results of separating the anomaly communities from the base regarding the fractal dimension differences. In this study, after saturation parameter modeling of a reservoir rock located in south of Iran, different communities were separated by kriging geostatistical method and using concentration-area fractal method. Based on the water saturation parameters, the results of fractal analysis represent two different communities in the reservoir.
\end{abstract}

Keywords Geostatistics · Variogram · Estimation · Kriging · Fractal geometry

\section{Introduction}

After investigations related to the Euclidean geometry, we found out that scientists searched for a kind of geometry that can describe all the processes present in nature considering that Euclidean geometry cannot cover most of the intricacies present in nature (Afzal et al. 2011). In recent years, the fractal geometry has well entered the technical fields (Fadakar Alghalandis 2004) in a way that geostatistics describes generalities, while the fractal describes the details (Abdideh and Rezaee 2017; Cheng 1999). Despite their short lifetimes, fractal methods, due to several reasons such as using all the data, considering their spatial dispersion and anomalies of geometric shapes, have efficient usages in superficial studies of geology and geochemistry (Asadi Harouni et al. 2013).

For a long time, the findings of traditional methods achieved from classical statistics have been considered as the only way to data analysis, but this way has had several shortcomings such as the condition of subordination to be

Mohammad Abdideh

m.abdideh@yahoo.com

1 Department of Petroleum Engineering, Islamic Azad University, Omidiyeh Branch, Omidiyeh, Iran normal, deleting some parts parts of data as out of the row, regardless of spatial distribution of data as well as anomalies of geometric shapes (Davis 2002; Abasalt and Hezar khani 2013). The above-mentioned problem have caused to employ new methods for data analysis that one of the most important methods is the fractal which will be discussed (Daya 2015a, b).

In this research, water saturation data related to 35 wells of an oil field in south west of Iran were investigated. After geostatistical modeling by kriging method and providing the distribution map of saturation parameter degree, modeling was accomplished via concentration-area multifractal method.

\section{Reservoir geology}

The studied reservoir rock is called Asmari formation. Asmari reservoir is the biggest and the most important reservoir rock in terms of oil production and storage in Iran (Abdideh and Rezaee 2017). Indeed, lithology is one of the most significant factors to determine water saturation type and its changes (Crain 2004). Therefore, the wells were examined by photoelectric diagram and photoelectric-density cross

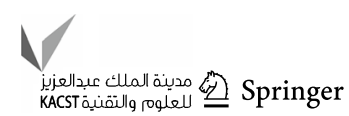


plots to determine the effect of this factor (Schlumberger 2000). Limestone is the dominant sort of lithology in all of the studied wells, and the traces of dolomite were seen in some of the wells. Petrophysically, heterogeneous limestone and most of its water saturation arise from tectonic factors such as faulting and diagenesis processes like fracture, dolomitization, and liquidation. Due to the above-mentioned reasons, the reservoir composed of such rocks does not show unified changes of water saturation (Fig. 1).

\section{Methodology}

In general, this research is divided into 3 distinct sections. First of all, parameter data of water saturation related to 35 wells of an oil field situated in south west of Iran were taken, and classical statistics assessments were conducted. Some concepts such as variance, average and histogram were analyzed in this section.

The results of the obtained models from the first section are the bases for the analyses in subsequent phases, and they have crucial roles in the conclusion.

In the second section, the distribution of water saturation parameter of all the reservoir layers is fulfilled by means of geostatistical measurements so the output of this section is the distribution map of water saturation of the reservoir rock.

In the final section, the results of prior measurements were studied on the basis of concentration-area fractal method. Then, by drawing logarithmic curve and finding the points change considering curve slope, different communities were recognized.

The software used in this study is GS+ which has the ability to study and analyze various geostatistical methods. This powerful software has different parts including classic statistics, analysis of variograms, and calculation of parameter distribution by Kriging method.

\section{Concentration-area fractal model}

Most of people have become familiar with Euclidean geometry principles during their education. Euclidean geometry is limited to study classical shapes present in nature, but rugged, disordered and nonclassic shapes and functions were marginalized by this geometry because of uncotrollability. In the twenty-first century, human beings have always been encountered the challenge of how to discipline the seemingly disordered natural phenomena to employ them in improving human life (Asadi Harouni et al. 2013). Since Euclidean geometry is not able to describe and formulate disordered shapes and substances (Mojtahed Zadeh et al. 2013), and it cannot explain intricacies present in nature, scientists have been in search of a kind of geometry that is able to explain all the processes present in nature (Afzal et al. 2011).

Professor Mandelbrot (1983) introduced fractal geometry for the first time as a capable instrument to achieve the mentioned goal. According to Mandelbrot (1983), fractal geometry explains the nature the same as the nature acts not as human beings want, and this is considered as a great advantage (Daya 2015a, b). Fractal geometry
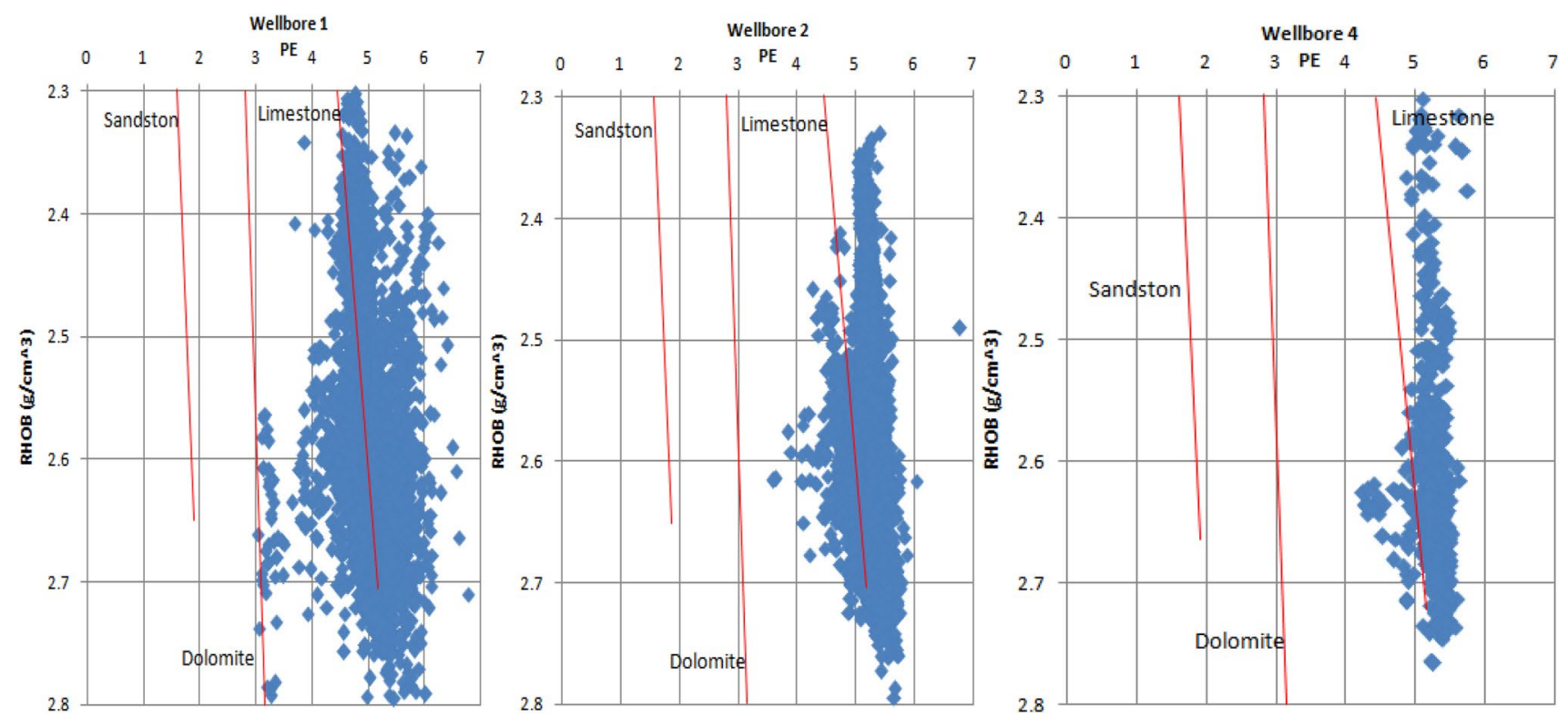

Fig. 1 Lithological distribution of the investigated reservoir rock on the basis of the petrophysical data 
represents each shape and its complexities by figures. Just like Euclidean geometry in which the concepts of angle, length, area, and -dimensional-to-three-dimensional spaces are employed (Agterberg 1995). The fractal geometry has fractal dimensions which are not ordinarily integers, and they are known as fractal dimensions used to explain intricacies of a shape (Agterberg et al. 1996). According to this, during in 1980s and 1990s, various methods of fractal analysis such as concentration-area, distance-area, concentration-environment, and exponent spectrum were presented that among them, concentration area has had many applications in engineering and earth sciences (Deng et al. 2010) (Abdideh and Rezaee 2017).

Concentration-area method introduced by Dr. Cheng Chini (1994) is based on the amount of area occupied by each specific concentration in the investigated region. As the concentration parameter increases, its occupied area decreases.

Nowadays, one of the most current methods to exhibit concentration distribution of a parameter is tracing contour map (rate curve) of the same concentration related to parameter in the investigated region (Cheng et al. 1994; Abdideh and Rezaee 2017).

If $\rho$ is considered as the amount of each concentration contour, we can present an exponential equation for concentrating material with fractal properties (Cheng et al. 1994; Abasalt and Hezar khani 2013) as follows:

$A(\geq \rho) \infty \rho^{-D}$.

$A(\geq v)$ is the cumulative area enclosed by the lines of the same concentration whose corresponding concentrations are greater than or equal to $v$. In fact, the value of $\alpha$ also represents the fractal dimension of the different $v$ domains.. By drawing variation of the area against concentration in logarithm graph, it is possible to calculate the dimension of each community through slope of trend line (Afzal et al. 2012). Failure points (slope change of the trend line) in the diagram display the change of one community to another (Abasalt and Hezar khani 2013) in a way that in addition to matrix separation, we can separate possible, probable, and certain anomalies of a parameter and even, in some cases, water saturation related to matrix from a water saturation of a fracture (Daya and Afzal 2015; Abdideh and Rezaee 2017). In other words, conversion of a community into another one indicates the tectonic, geological, and lithological conditions in the reservoir rock. Fractal essence of elements distribution in nature causes such unique ability so that we will not need to remove out of the row amounts anymore; because due to the fractal essence of the data, they are excluded automatically (Abasalt and Hezar khani 2013; Abdideh and Rezaee 2017; Hassan Pour and; Afzal 2013; Agterberg et al. 1996; Goncalves et al. 2001).
Mono fractal arising from the nature of fractal distribution of the rock parameters and the kind relationship between concentration and included area are displayed in the form of an exponential function. This means that concentration-area logarithmic diagram represents the number of steps in forming parameter of rocky properties of reservoir such as water saturation as well as secondary distribution of this parameter in the investigated region. Using this, we can find out geological conditions in the investigated reservoir more than ever. Certainly, by monofractal modeling and incorporating its results with geology data, an ideal interpretation of static modeling of the investigated rock can be obtained (Abdideh and Rezaee 2017).

\section{Results and discussion}

In the first step, having the data of the intended parameter is necessary. In this research, water saturation parameter related to 35 wells of an oil field located in south west of Iran with the coordinates are available (Fig. 2).

Histogram diagrams and cumulative frequency give us valuable information about the investigated statistical parameters and changes (such as standard deviation, sample variance, the smallest and the biggest amount, the number of samples, skewness and elongation of the data). The parameter is examined regarding normality or abnormality. Normalization is the next step followed by tracing varoigram to estimate properly by measuring and selecting the best variogram and taking the required information from variogram. Variogram investigates the structural analysis and spatial modeling of the water saturation degree parameter in sampling environment (Goncalves et al. 2001) (Fig. 3).

The discontinuity between 12 and 18 categories indicates the desultory data (that means there are mistakes in

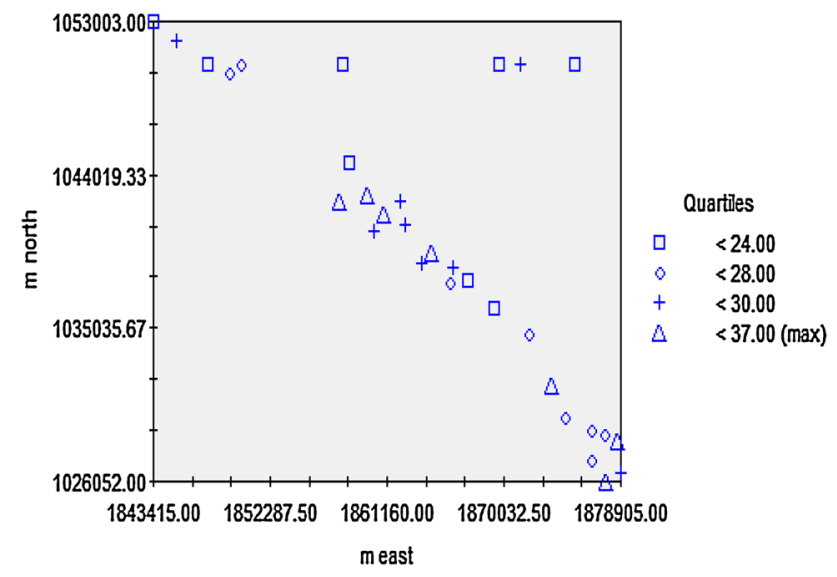

Fig. 2 Determining each well in the sampling environment

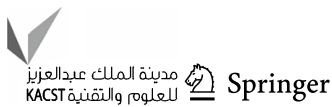


NonTransformed

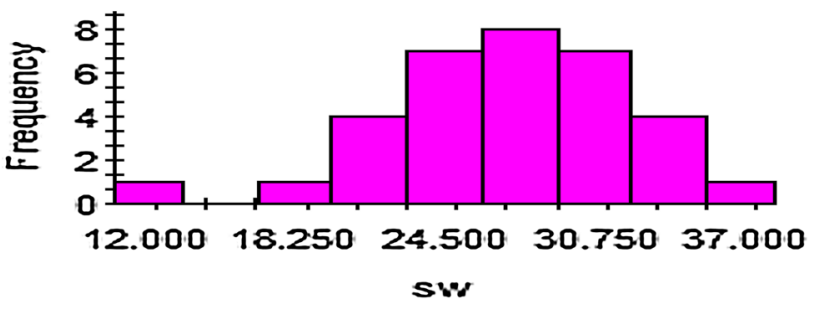

Fig. 3 Histogram of the water saturation data. The frequency distribution curve related to the water saturation data

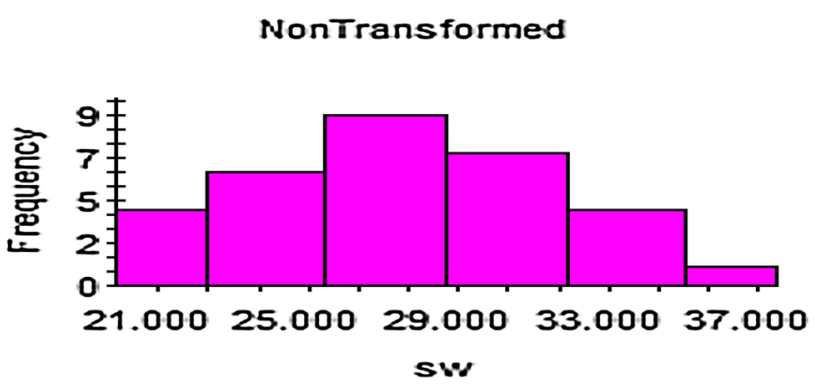

Fig. 4 Frequency distribution curve related to the water saturation data with removing 12 and 17

laboratory, sampling or in reservoir rock naturally that the existence of fracture or faulting can cause this situation).

Figure 4 after omitting the numbers 17 and 12 from the water saturation data, the histogram presents almost normal distribution of the water saturation data in the reservoir rock.

Spatial relation among amounts of a quantity in a selected samples community with mathematic frames is called spatial structure. The spatial relation is examined in terms of distance and direction. In geostatistics, those variables that have spatial structure are investigated. In other words, reservoir data should have mathematical relations in a certain distance and direction with each other. The data are known as the structured data. The total variability of a component is regarded in the classical statistics, but in geostatistics, some parts are random, and the others are structured. This concept is investigated by an instrument which is called variogram. In fact, variogram acts as a filter which means that it can separate the related spatial data (the structured component) from the nugget data, and this is the most important concept in building reservoir statistic model.

Figure 5 displays variogram of the water saturation data. As you see, the exponential model- the best kind of variogram- has been selected. (This variogram has sill and the nugget effect of near zero).

The above variogram reveals complete overcome of nugget effect part by the structured part, and it denotes the strong spatial structure of the investigated zone (water saturation).

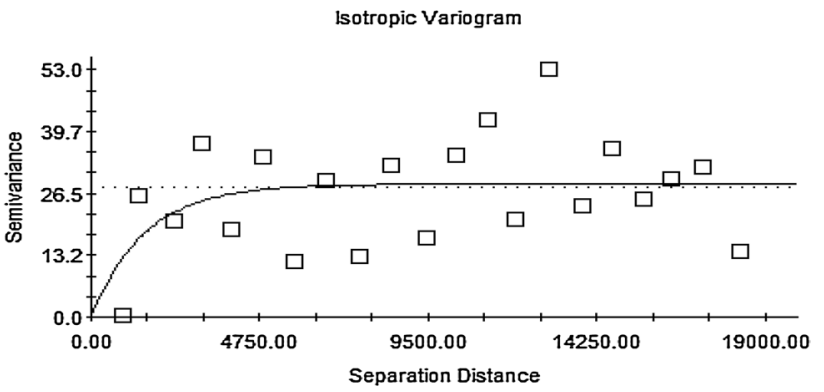

Fig. 5 Variogram diagram related to the water saturation data

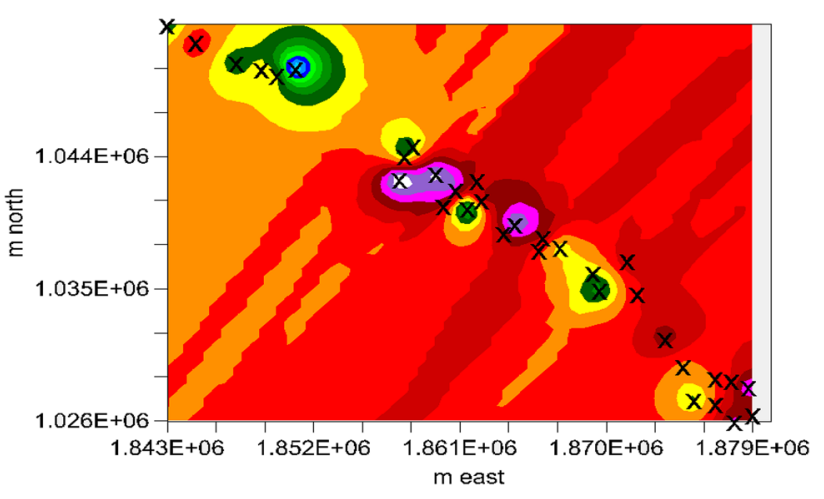

Fig. 6 Estimation of water saturation by the Kriging method

After specifying spatial structure via diagram analysis, the next step is estimating water saturation parameter for all the reservoir layer. Kriging is one of the best methods for providing distribution map. Kriging is the best linear unbiased estimator with the least variance which shows errors simultaneously. Consequently, not only average of errors can be calculated but also the errors of the entire zone can be checked. Kriging is an estimation method based on weighted moving average (i.e., gives its weight to data) that has final conditions which means independence of the average from the coordinate and lack of proceeding. Through this method, by considering the spatial structure and the specific amount of reservoir quantities, we estimate unknown points of the reservoir.

Figure 6 displays the estimation map of water saturation parameter of kriging method in the investigated reservoir. The estimation by kriging methods indicates the most qualified part of the reservoir rock in terms of SW parameter located in north west of the reservoir.

After estimating the distribution of each parameter, the estimation validity should be conducted. One of the best methods for validation is removing the known data randomly and estimating them by the method used for the estimation.

Figure 7 shows a diagram that displays actual data compared to estimated data. The closer the best line crossed 


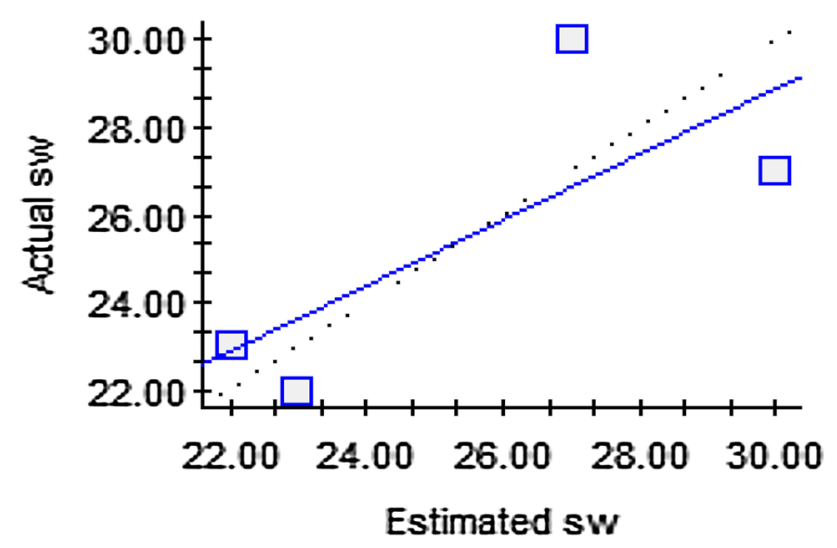

Fig. 7 Validation of water saturation estimation by the Kriging method

among data to 45 degree, the more valid the estimation method.

Regarding the diagram of Fig. 7, the slope of the blue line is about 60 degrees that the estimated line slope can be near the real line by changing radius and neighbors. This means that the kriging method shows reliable validation in estimating water saturation parameter.

According to concentration-area fractal model, two petrophysical data communities of water saturation are shown for logarithmic diagram. Each of the two communities has spatial distribution. In other words, fractal classifies water saturation data like a filter, based on different formation situations. These situations can be resulted from lithological changes or geological secondary parameters such as fracture.

To achieve accurate regional distribution of water saturation, the same intensity map of water saturation in software is provided (Fig. 6), and the enclosed area of each concentration is calculated according to the map. For calculating the area corresponding with each concentration, the data are categorized first. Then, considering the measured areas for each concentration, concentration-area curve is traced cumulatively and the lines on the fractal curve are trended.

In this study, after ordering data from high to low and determining the frequency of each datum, the cumulative frequency diagram of water saturation was drawn (Fig. 8) then communities and threshold limit anomalies from matrix were determined by trending straight lines to points series and specifying failure point on the line (Fig. 9). The matrix means that the amount of water saturation related to rock matrix and anomalies means the amount of water saturation resulted from the secondary geological processes.

If the fractal diagram has one fracture point (that means it has two communities), it is known as monofractal.

According to Fig. 9, there are two specified communities which are results of the change in crossing lines. Consequently, water saturation parameter in the reservoir rock

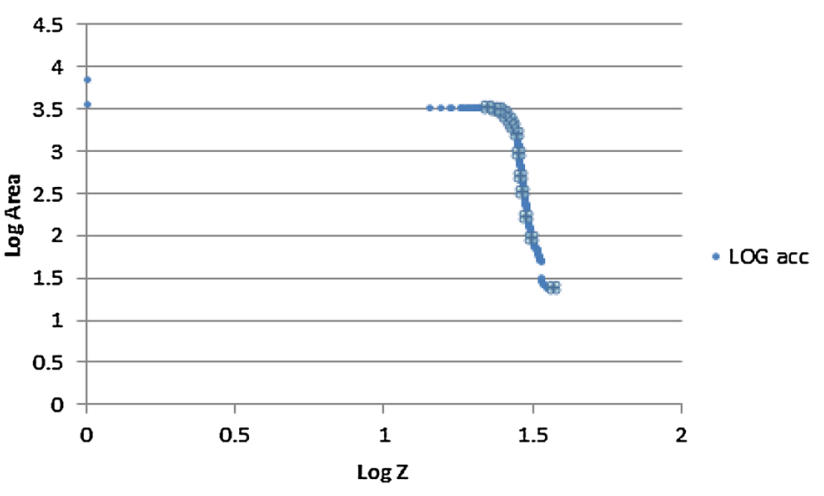

Fig. 8 Full logarithmic fractal diagram of concentration-area

has monofractal distribution. Investigating the achieved lines slopes from concentration-area of mono fractal diagram related to water saturation, the geological concepts of the investigated reservoir can be determined.

In the diagram of Fig. 9, the line with minimum slope near horizon is related to the rock matrix and the line with maximum slope close to upright is related to the secondary geological parameters that have effects on reservoir rock such as fractures. The threshold limit of the horizontal line has been specified with another oversloped line in Fig. 9.

\section{Conclusion}

This study revealed that multifractal method of concentration-area is a very accurate method in reservoir statistical modeling, it specifies cases hidden in other petrophysical methods. By implementing this method, anomalies and specified communities for water saturation parameter were properly verified with geological evidences, especially effects of fractures, faulting or other factors in reservoir rock.

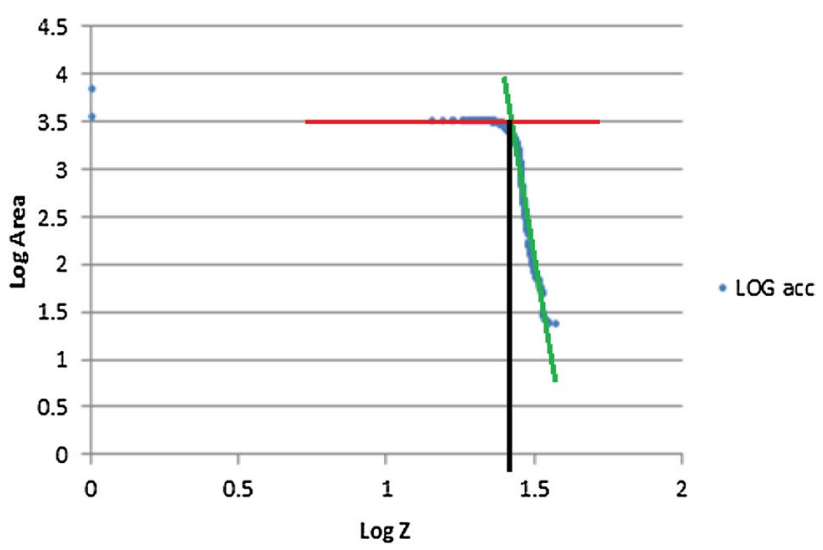

Fig. 9 Determining the threshold limit 
The specified result of this research can be summarized as follows:

1. The spatial analysis by means of variogram shows strong structure of water saturation parameter in reservoir rock.

2. Based on the traced variogram of the achieved model, exponential model has minimum nugget effect, low ceiling, and maximum domain effect.

3. Primary data of water saturation have almost normal distribution that makes geological modeling more accurate.

4. The estimation by kriging method illustrates the most qualified part of the reservoir rock in terms of SW parameter located in northeswestt of the reservoir.

5. Fractal modeling by concentration-area method illustrates two different communities of water saturation parameter.

6. Investigating the two communities resulted from fractal modeling demonstrates that the community with minimum slope near the horizon is related to rock matrix, and the community with maximum slope near upright is related to the secondary geological parameters that have influence on reservoir rock, such as fractures.

7. Investigating concentration-area fractal model and obtaining cross plot results, it is concluded that water saturation parameter is monofractal in reservoir rock.

Open Access This article is distributed under the terms of the Creative Commons Attribution 4.0 International License (http://creativeco mmons.org/licenses/by/4.0/), which permits unrestricted use, distribution, and reproduction in any medium, provided you give appropriate credit to the original author(s) and the source, provide a link to the Creative Commons license, and indicate if changes were made.

\section{References}

Abasalt F, Hezar Khani A (2013) "Geological anomaly separation of matrix by concentration-area fractal method", Anguran region, northwest of Iran. Adv J Geol 9:109-120 (in Persian)

Abdideh m, Rezaee H (2017) Separation of rock types in reservoir rock using concentration-area multifractal model. Geosyst Eng 20(6):348-354

Afzal P, Khakzad A, Maaref Vand P, Rashid Nejad NA, Asadi Harouni H, 2011, Separation of mineralization zones in Kahang porphyritic copper deposit situated in Isfahan by means of modern concentration-volume fractal method, J Earth Sci 20(81):95-112

Afzal p, Zarifi AZ, Farhadi S, Wetherelt A, Yasrebi BA (2012) "Separation of Uranium anomalies based on geophysical airborne analysis by using concentration-Area (C-A) fractal model", Mahneshan 1:50000 sheet, NW Iran. J Mining Metall 48(1):1-12

Agterberg FP (1995) Multifractal modeling of the sizes and grades of giant and supergiant deposits. Int Geol Rev 37(1):1-8
Agterberg FP, Cheng Q, Brown A, Good D (1996) "Multifractal modeling of fractures in the Lac du Bonnet batholith, Manitoba. Comput Geosci 22(5):497-507

Asadi Harouni H, Mokhtari AR, Afzal P (2013) "Modeling and analysis of reserve by means of concentration-volume fractal method in south division of Dali porphyritic copper-gold deposit located in Markazi province". Master's Thesis (in Persian)

Cheng QM (1999) Spatial and scaling modeling for geochemical anomaly separation. J Geochem Explor 65(3):175-194

Cheng QM, Agterberg FP, Ballantyne SB (1994) The separation of geochemical anomalies from background by fractal methods. J Geochem Explor 51(2):109-130

Crain ER (2004) Crain's petrophysical handbook: Canada, Spectrum 2000 Mindware, 3rd Millennium Edition. http://www.spec2000. net/lcmain.htm

Davis JC (2002) Statistics and data analysis in geology. Wiley, New York, $\mathrm{p} 638$

Daya AA (2015a) "Application of concentration-area method for separating geochemical anomalies from background: a case study of Shorabhaji region", northwest of Iran. Arab J Geosci 8:3905-3913

Daya AA (2015b) "Comparative study of C-A, C-P, and N-S fractal methods for separating geochemical anomalies from background: a case study of Kamoshgaran region", northwest of Iran. J Geochem Explor 150:52-63

Daya AA, Afzal. P (2015) "A comparative study of concentrationarea (C-A) and spectrum-area (S-A) fractal models for separating geochemical anomalies in Shorabhaji region", NW Iran. Arab J Geosci 8:8263-8275

Daya AA, Boomeri M, Mazraee (2016) Identification of geochemical anomalies by using of concentration-area (C-A) fractal model in Nakhilab Region”, SE Iran. J Min Miner Eng 8(1):70. https://doi. org/10.1504/IJMME.2017.082694

Deng J, Wang Q, Yang L, Wang Y, Gong Q, Liu H (2010) “Delineation and explanation of geochemical anomalies using fractal models in the Heqing area, Yunnan Province", China. J Geochem Explor 105(3):95-105

Fadakar Alghalandis Y (2004) "Function of exponent-area spectrum fractal method for anomaly separation of matrix", Iran Mining Engineering Conference. Tehran (in Persian)

Goncalves MA, Mateus A, Oliveira V (2001) Geochemical anomaly separation by multifractal modeling. J Geochem Explor 72(2):91-114

Hassanpour S, Afzal P (2013) "Application of concentration-number (C-N) multifractal modeling for geoc-hemical anomaly separation in Haftcheshmeh porphyry sys-tem", NW Iran. Arab J Geosci 6(3):957-970

Mohammad Torab F, Koohsari AH (2010) Interpreting geochemical data of Jolfa region and using fractal method for anomaly separation of matrix. Master's thesis (in Persian)

Mojtahed Zadeh SH, Ghorbani A, Koohsari AH (2013) Comparing functions of different fractal methods for geochemical anomaly separation, the case study: Zafrand copper index located in Isfahan. Master's thesis (in Persian)

Schlumberger (2000) Log Interpretation Charts, 2000 edn

Publisher's Note Springer Nature remains neutral with regard to jurisdictional claims in published maps and institutional affiliations. 